years of age. The above report identifies a kindred with PM-Like D, clinically resembling PMD, but with intact myelin and with mutations at a new locus on the $\mathrm{X}$ chromosome.

\title{
SPINAL MUSCULAR ATROPHY AND ARTHROGRYPOSIS
}

Four infants with neurogenic arthrogryposis who died of respiratory failure before 1 month of age had DNA testing of autopsy specimens for $S M N^{T}$ gene deletion in a study at the Children's Hospital of Philadelphia, PA, and the Children's Hospital at Dartmouth, Lebanon, NH. All infants had clinical, pathologic, or EMG evidence of motor neuron disease. In addition to anterior horn cell loss, autopsies showed a more extensive neurodegeneration involving central sensory neurons in Clarke's column and the thalamus. $S M N^{T}$ deletion was identified in two of the cases. (Bingham PM, Shen N, Rennert H et al. Arthrogryposis due to infantile neuronal degeneration associated with deletion of the $S M N^{T}$ gene. Neurology Sept 1997;49:848-851). (Reprints: Dr PM Bingham, Division of Child Neurology, Children's Hospital of Philadelphia, Philadelphia, PA 19104).

COMMENT. Arthrogryposis in association with infantile spinal muscular atrophy (Werdnig-Hoffmann disease) was first reported by Byers and Banker (1961). DNA analysis for $S M N^{T}$ deletion in cases of neurogenic arthrogryposis may uncover a diagnosis of spinal muscular atrophy or SMA variant and facilitate genetic counselling. Some cases of infantile SMA may have degenerative changes in sensory neurons in addition to the classical anterior horn cell loss.

Congenital axonal neuropathy with $S M N$ deletion is reported in three newborn siblings presenting with generalized weakness, asphyxia, facial diplegia, and external ophthalmoplegia, and studied at Pediatric University Hospital, Mathildenstr, Freiburg, Germany (Korinthenberg R, Sauer M, Ketelsen U-P et al. Ann NeurolSept 1997;42:364-368). EMG, NCV, and nerve biopsies confirmed an axonal neuropathy. The electrophysiological and biopsy findings, together with the $S M N$ gene deletion, were diagnostic of a severe spinal muscular atrophy, complicated by involvement of brainstem nuclei and sensory nerves. Contrary to accepted criteria, weakness of extraocular muscles and facial weakness do not exclude the diagnosis of SMA.

\section{VASCULAR DISORDERS}

\section{FACTOR V LEIDEN MUTATION AND NEONATAL STROKE}

Three infants with familial factor $V$ Leiden mutation and neonatal cerebrovascular disorders are reported from the Children's Hospital of Philadelphia, PA. One had placental thrombosis. Activated protein $\mathrm{C}$ resistance caused by factor $\mathrm{V}$ Leiden mutation is an important cause of in utero ischemic infarction and hemorrhagic stroke and may present with neonatal hemiplegic cerebral palsy. (Thorarensen O, Ryan S, Hunter J, Younkin DP. Factor V Leiden mutation: an unrecognized cause of hemiplegic cerebral palsy, neonatal stroke, and placental thrombosis. Ann Neurol Sept 1997;42:372-375). (Dr Younkin, Division of Neurology, 6th Floor, Wood Bldg, Children's Hospital of Philadelphia, 34th St and Civic Center Blvd, Philadelphia, PA 19104).

COMMENT. Infants with hemiplegic cerebral palsy caused by a vascular accident should be tested for factor $\mathrm{V}$ Leiden mutation, especially if a parent 